\title{
Wire Laser Arc Additive Manufacture of aluminium zinc alloys
}

\author{
E. Eimer ${ }^{1} \cdot$ W. Suder ${ }^{1} \cdot$ S. Williams ${ }^{1} \cdot$ J. Ding ${ }^{1}$
}

Received: 12 October 2019 / Accepted: 24 February 2020 / Published online: 11 March 2020

(C) The Author(s) 2020

\begin{abstract}
Aluminium zinc alloys are widely used in the aerospace industry due to their high strength. However, only a few studies have been reported on the additive manufacture of aluminium zinc alloys. This rarity is due to the difficulties occurring during the fusion processing of these alloys and to the lack of available raw material. This paper presents an alternative process used for the deposition of aluminium zinc alloys. In this study, a Wire Laser Arc Additive Manufacture (WLAAM) system was used. This consisted of a gas metal arc power source, used to generate the melt pool, and a laser beam applied to control the melt pool size. By using this approach, it was possible to produce an elongated melt pool and feed zinc into it with a cold wire without compromising the process stability. A welding camera along with a system measuring the arc voltage and current was used to monitor the process. Different process parameters and configurations were investigated along with their effect on process stability and deposited material microstructure. A very high zinc concentration was achieved in the deposited material without macro-segregation.
\end{abstract}

Keywords Additive manufacturing $\cdot$ DED $\cdot$ Aluminium $\cdot$ Zinc

\section{Introduction}

Wire and Arc Additive Manufacture (WAAM) is a Direct Energy Deposition (DED) process using a wire as the feed material and an electric arc as the heat source to deposit large-scale 3-dimensional components. WAAM benefits from a large reduction of material wastage and lead-time compared with subtractive processes [1]. High strength aluminium alloys are widely used in aerospace because of their high strength to density ratio as well as great damage tolerance and corrosion resistance [2]. High strength aluminium alloys can be divided into two families: aluminium copper and aluminium zinc alloys, classified as 2000 and 7000 series respectively. As for many other materials, aluminium alloys can be deposited with WAAM and aluminium component can benefit from these process advantages [3].

Recommended for publication by Commission I - Additive Manufacturing, Surfacing, and Thermal Cutting

This article is part of the Topical collection on Additive Manufacturing Processes, Simulation and Inspection

E. Eimer

e.eimer@cranfield.ac.uk

1 Welding Engineering and Laser Processing Centre, Cranfield University, Bedford MK43 0AL, UK
The possibility of depositing high strength aluminium alloys has been demonstrated and reported in numerous studies. Most studies focus on the deposition of 2319 alloy. It is a common aluminium copper welding wire and is perfectly suitable for WAAM [4-8]. The deposition of aluminium copper magnesium was also reported by $\mathrm{Gu}$ et al. and Qi et al.: because of the lack of available wires of these grades, the authors used tandem systems to mix wires of different grades to achieve a wide range of deposited material compositions $[9,10]$.

However, to the best of the author's knowledge, no study has been reported on the WAAM deposition of aluminium zinc alloys. This lack of previous work can easily be explained: despite the attractiveness of aluminium zinc alloy properties, these alloys can appear to be incompatible with WAAM. Indeed, no aluminium zinc filler wire is available on the market due to the high hot cracking sensitivity of these alloys and the behaviour of zinc in an electric arc. As reported by Wood [11], the low boiling point of zinc causes zinc to vaporise during Gas Metal Arc (GMA) welding with an aluminium zinc wire: this greatly disturbs the arc and can generate a high porosity level and depletion of zinc in the weld bead.

Despite the low boiling point of zinc and the high sensitivity of hot cracking of 7000 series alloys, few studies have been conducted on the use of Powder Bed Fusion (PBF) processes to manufacture components with aluminium zinc alloys. Martin et al. studied the effect of zirconium addition on the hot cracking sensitivity of the 7075 alloy. The authors 
demonstrated the possibility of using a modified $7075+\mathrm{Zr}$ alloy with PBF to manufacture crack-free samples [12]. Aversa et al. mixed 7075 powder with AlSi10Mg powder, widely used in $\mathrm{PBF}$, and were also able to produce crack free-material [13].

These recent studies on the development of aluminium zinc alloys for PBF confirm the emerging interest for these alloys for additive manufacturing (AM) applications. However, the scarcity of raw material in wire form and the behaviour of zinc in the arc is a stumbling block to the development of aluminium zinc deposition by WAAM. To overcome the lack of available filler, a multiple wire approach can be used, just as for the development of aluminium copper magnesium alloy previously cited $[9,10]$. To avoid the consequences of zinc vaporisation in the arc, the filler wire containing zinc should be fed in the melt pool away from the arc. For this, an elongated melt pool is required. Aluminium alloys solidify very quickly; therefore, an aluminium melt pool in WAAM is usually small and mainly situated directly under the arc: this leaves no space to feed a wire in the melt pool away from the arc.

This paper reports the initial development of Wire Laser Arc Additive Manufacture (WLAAM) for aluminium zinc deposition. The first objective was to determine if this process could be used to achieve an elongated and stable melt pool. The second objective was to produce some aluminium zinc samples using WLAAM.

\section{Experimental procedure}

The Wire Laser Arc Additive Manufacture process consisted of a GMA torch and a laser beam as heat sources: the leading GMA torch generated a melt pool using a 2319 wire, and the trailing laser beam was applied to this melt pool. An IPG YLR-8000 continuous wave fibre laser and a Fronius CMT advanced 4000R power sources were used. Figure 1 is a diagram of the experimental arrangement: it shows the different distances between the heat sources and the zinc cold wire. Single beads and three layer high structures were deposited on 2219 substrate. The 2219 and 2319 alloys were considered as binary aluminium copper alloys with a copper content of $6.3 \mathrm{wt} \%$ (wt\%), a $99.95 \mathrm{wt} \%$ zinc cold wire was used. The 2319 and zinc wire diameters were $1.2 \mathrm{~mm}$ and $1.6 \mathrm{~mm}$ respectively.

Various deposition parameters were used: Table 1 gives the constant parameters used as well as the range of value used for each parameters which varied.

To evaluate the process stability, a Redman welding camera was used to visualise the melt pool and metal transfer. The GMA deposition stability was monitored using an AMV 5000 system which recorded both arc voltage and current during deposition. Cross sections of the deposited layers were cold

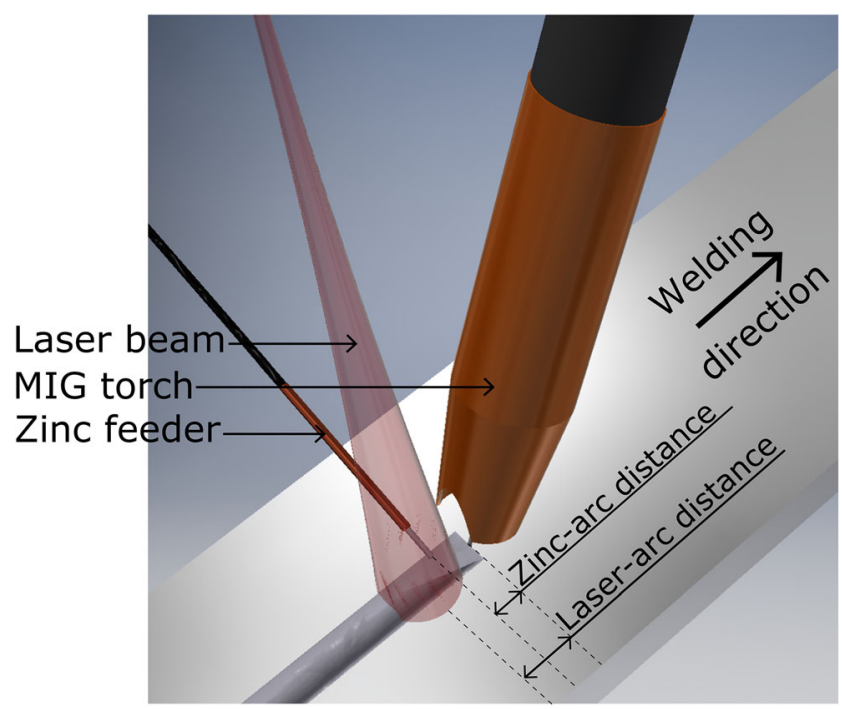

Fig. 1 Setup diagram

mounted, ground, polished to a mirror finish, and etched with Keller's etchant. A Nikon Optiphot microscope was used for optical imaging, and an XL30 Scanning Electron Microscope (SEM) with an X-MAX ${ }^{\mathrm{N}}$ detector was used for Energydispersive X-ray Spectroscopy (EDS) and element mapping.

The following sections provide the specific deposition parameters used in the different parts of section 3 .

\subsection{Wire Laser Arc deposition}

In this section, a constant $\mathrm{WFS}_{[2319]}$ of $7 \mathrm{~m} / \mathrm{min}$ and a laser-arc distance of $10 \mathrm{~mm}$ were used. Two cases were investigated: one with no laser, referred to as "arc only", and one with laser, referred to as "laser assisted arc". The effect of laser on the bead shape and melt pool length was observed. The same deposition parameters were used for the study of laser-arc distance. The process stability was characterised using videos and arc voltage data.

Table 1 General deposition parameters

\begin{tabular}{ll}
\hline GMA torch trailing angle & $30^{\circ}$ \\
Laser beam trailing angle & $5^{\circ}$ \\
Travel speed & $10 \mathrm{~mm} / \mathrm{s}$ \\
Laser beam spot size & $9.5 \mathrm{~mm}$ \\
Shielding gas & $25 \mathrm{~L} / \mathrm{min}$ \\
WFS $_{[2319]}^{1}$ & 5 to $9 \mathrm{~m} / \mathrm{min}$ \\
WFS $_{[\mathrm{Zn}]}^{2}$ & 0 to $2 \mathrm{~m} / \mathrm{min}$ \\
Laser power $^{2}$ & 0 to $5 \mathrm{~kW}$ \\
\hline
\end{tabular}

${ }^{1} 2319$ Wire Feed Speed

${ }^{2}$ Zinc Wire Feed Speed 
Table 2 Deposition parameters for aluminium zinc deposition

\begin{tabular}{lllll}
\hline Samples & Laser power $[\mathrm{kW}]$ & $\mathrm{WFS}_{[2319]}[\mathrm{m} / \mathrm{min}]$ & $\mathrm{WFS}_{[\mathrm{Zn}]}[\mathrm{m} / \mathrm{min}]$ & $\begin{array}{l}\text { Calculated zinc } \\
\text { concentration }{ }^{2} \text { [weight \%] }\end{array}$ \\
\hline $\mathrm{A}$ & 2 & 8 & 1.2 & 37 \\
$\mathrm{~B}^{1}$ & 2 & 9 & 1.2 & 37 \\
$\mathrm{C}$ & 3 & 9 & 1.2 & 50 \\
$\mathrm{D}$ & 3 & 9 & 2.0 & 37 \\
$\mathrm{E}$ & 3 & 6 & 1.2 & 47 \\
$\mathrm{~F}^{1}$ & 5 & 6 & 1.2 & 47 \\
$\mathrm{G}^{1}$ & 3 & 10 & 2.0 & 50 \\
\hline
\end{tabular}

${ }^{1}$ Parameters used to deposit three layer high walls

${ }^{2}$ Calculated without considering any element losses

\subsection{Addition of zinc}

In this section, the set-up configuration was fixed: the laser-arc and arc-zinc distances were set at 10 and $7 \mathrm{~mm}$ respectively. The $\mathrm{WFS}_{[2319]}, \mathrm{WFS}_{[\mathrm{Zn}]}$, and laser power were changed as indicated in Table 2. Single beads were deposited, and the best three set of parameters were selected to deposit three layer high walls.

The expected zinc content was calculated using the following equations:

$$
\begin{aligned}
M_{[\mathrm{Zn}]} & =\operatorname{WFS}_{[\mathrm{Zn}]} * \rho_{[\mathrm{Zn}]} * \pi * d_{[\mathrm{Zn}]}^{2} / 4 \\
M_{[\mathrm{Al}]} & =\operatorname{WFS}_{[2319]} * \rho_{[\mathrm{Al}]} * \pi * d_{[2319]}{ }^{2} C_{[\mathrm{Al}]} / 4 \\
M_{[\mathrm{Cu}]} & =\operatorname{WFS}_{[2319]} * \rho_{[\mathrm{Cu}]} * \pi * d_{[2319]}{ }^{2} C_{[\mathrm{Cu}]} / 4 \\
W_{[\mathrm{Zn}]} & =M_{[\mathrm{Zn}]} /\left(M_{[\mathrm{Zn}]+} M_{[\mathrm{Al}]+} M_{[\mathrm{Cu}]}\right)
\end{aligned}
$$

With $M_{[X]}, \rho_{[X]}, C_{[X]}$ the mass per unit length of deposit, the density, and the concentration in the wire of the element $X$; $d_{[\mathrm{Zn}]}$ and $d_{[2319]}$ the diameters of the $\mathrm{Zn}$ and 2319 wires; and $W_{[\mathrm{Zn}]}$ the weight $\%$ of zinc in the deposited material. These equations were used to calculate the zinc concentration in the deposit without considering any zinc loss by vaporisation during the process. The $\mathrm{WFS}_{[\mathrm{Zn}]}$ was limited by the process stability: at too low WFS, the zinc transfer was very irregular. Due to the large zinc wire diameter, this led to very high zinc calculated content in the bead, up to $50 \%$ compared with the usual $7 \%$ found in aluminium zinc alloy.

\section{Results and discussion}

\subsection{Wire Laser Arc deposition}

This section reports preliminary observations made during the use of the Wire Laser Arc process without zinc addition.

Figure 2 shows the effect of the additional energy from the laser on the arc bead. All other parameters were kept constant. The increase in energy led to an increase of the bead width, penetration depth, and melted area due to an increase in heat input.

Figure 3 shows the termination point of two single beads deposited with the same parameters using arc only and laserassisted arc (laser power of $2 \mathrm{~kW}$ ). The termination point indicates the length of the melt pool, as shown in Fig. 3: the melt pool length increases in the laser-assisted arc case.

Another critical parameter for the melt pool length is the laser-arc distance. When the two heat sources were too close, overheating of the GMA torch was observed. However, when the laser-arc distance was increased, the melt pool length increased as well: for a laser-arc distance of $15 \mathrm{~mm}$, the melt pool length was $23.8 \mathrm{~mm}$ compared with $19.8 \mathrm{~mm}$ for a distance of $10 \mathrm{~mm}$. Figure 4 a shows the uniform melt pool with regular edges obtained with a laser-arc distance of $10 \mathrm{~mm}$. But, for a laser-arc distance of $15 \mathrm{~mm}$, picture (b) shows that the melt pool became wider behind the arc and was split into two parts. This separation generated many instabilities due to the interactions between the two melt pools.
Fig. 2 Bead shape obtained with arc only (a) and laser-assisted arc (b) (laser power of $4 \mathrm{~kW}$ )

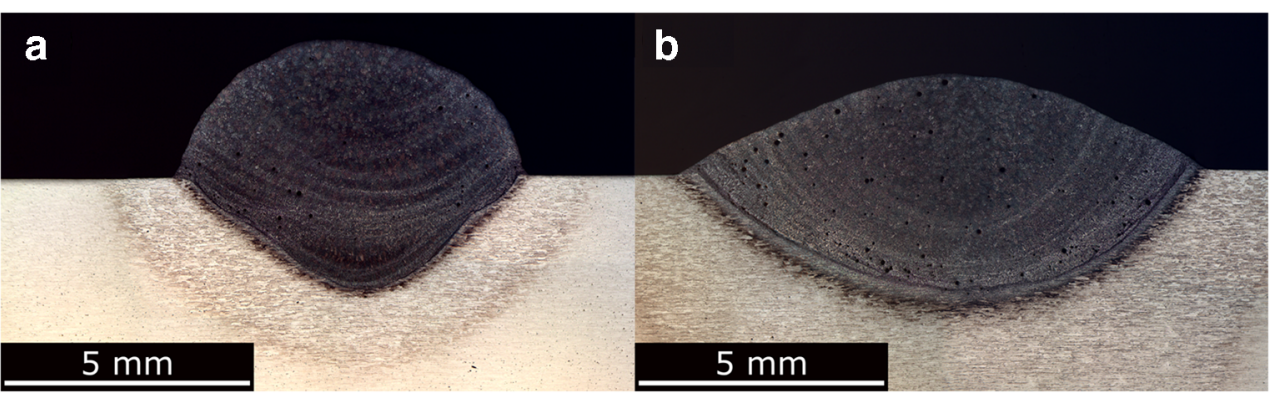




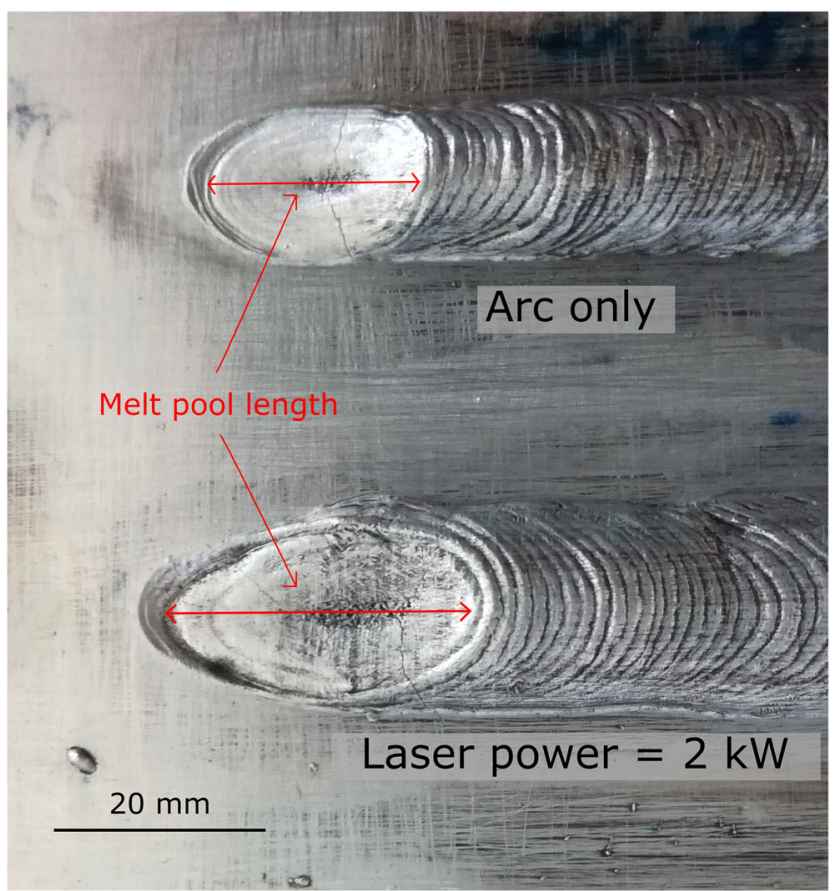

Fig. 3 Melt pool length for both arc only and laser-assisted arc cases (laser power of $2 \mathrm{~kW}$ )

Nevertheless, when appropriate laser-arc distances were used, some benefits of the laser beam on the process stability were observed. Figure 5 shows the voltage of the arc measured during the deposition with the arc only and laserassisted arc with a laser-arc distance of $10 \mathrm{~mm}$. Some arc instabilities can be seen when the arc only was used, but in the laser-assisted arc case, the process stability was considerably improved as shown by the lack of spikes in the voltage trace.

In summary, it is possible to use Wire Laser Arc process to elongate the melt pool otherwise obtained by GMA alone. Increasing the laser power and the laser-arc distance are ways of increasing the melt pool length as much as required. However, the laser power has a great effect on the bead shape and the laser-arc distance affects the process stability. These phenomena need to be taken into account to deposit aluminium zinc with using a cold wire.
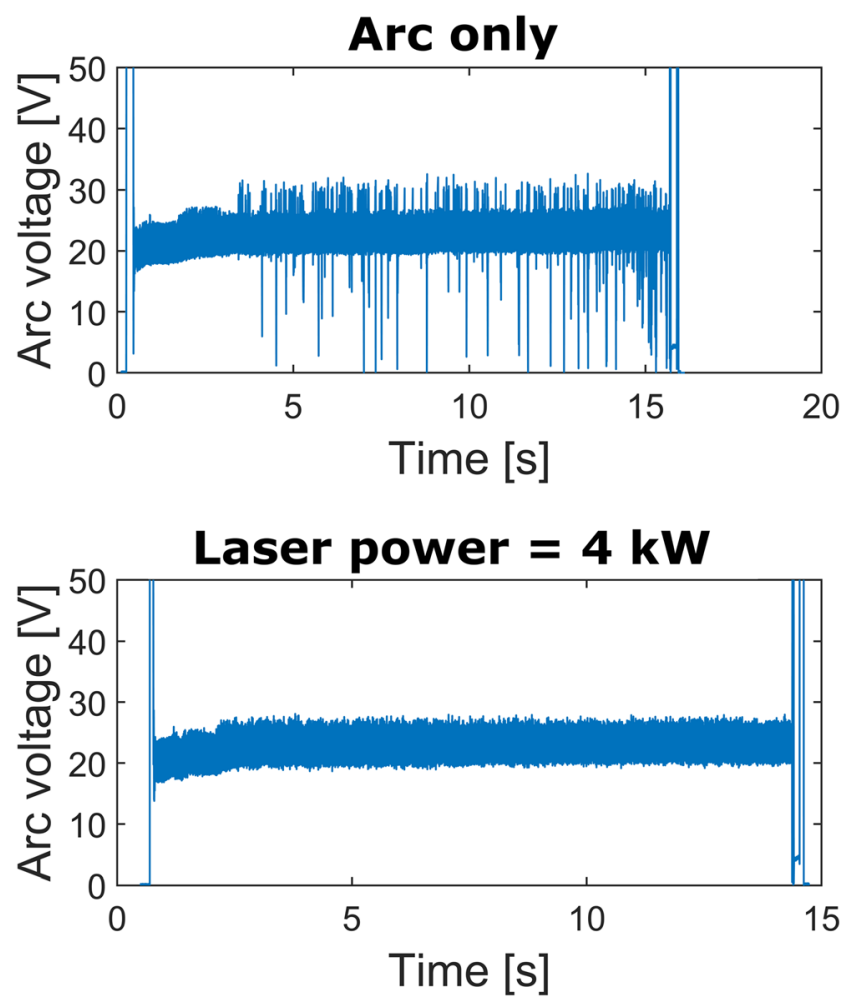

Fig. 5 Effect of laser on arc voltage for a laser-arc distance of $10 \mathrm{~mm}$

\subsection{Addition of zinc}

The addition of zinc was made possible by the melt pool elongation. As mentioned in section 2.2, the $\mathrm{WFS}_{[\mathrm{Zn}]}$ was chosen in order to obtain a constant metal transfer during deposition. This led to a low $\mathrm{WFS}_{[2319]} / \mathrm{WFS}_{[\mathrm{Zn}]}$ ratio and resulted in unbalanced chemical compositions in the deposited material. As detailed in Table 2, the zinc content of the material was expected to be as high as $50 \mathrm{wt} \%$, which is much higher than the usual 5 to $8 \mathrm{wt} \%$ found in aluminium zinc alloys. For this reason, no extensive study of the deposited material solidification behaviour and mechanical properties was conducted.

The process parameters greatly affected the bead shape and zinc macro segregation. Figure 6 a shows that too low heat input resulted in incomplete melting of the zinc wire. This
Fig. 4 Effect of laser-arc distance on melt pool shape with a distance of $10 \mathrm{~mm}$ (a) and $15 \mathrm{~mm}(\mathbf{b})$
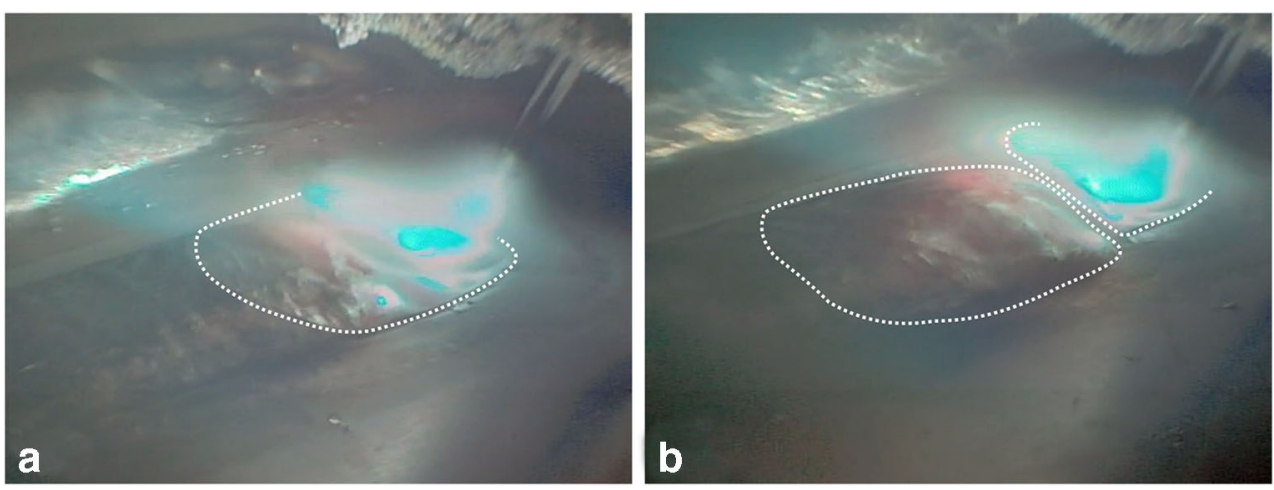
Fig. 6 Microstructures of beads at constant WFSs and laser power of $2 \mathrm{~kW}$ (a) (sample E in Table 2) and $5 \mathrm{~kW}$ (b) (sample $\mathrm{F}$ in Table 2)

Fig. 7 Microstructures of beads at constant laser power and with a WFS $_{[2319]}$ of $8 \mathrm{~m} / \mathrm{min}$ (a) (sample A in Table 2) and $9 \mathrm{~m} / \mathrm{min}(\mathbf{b})$ (sample B in Table 2)
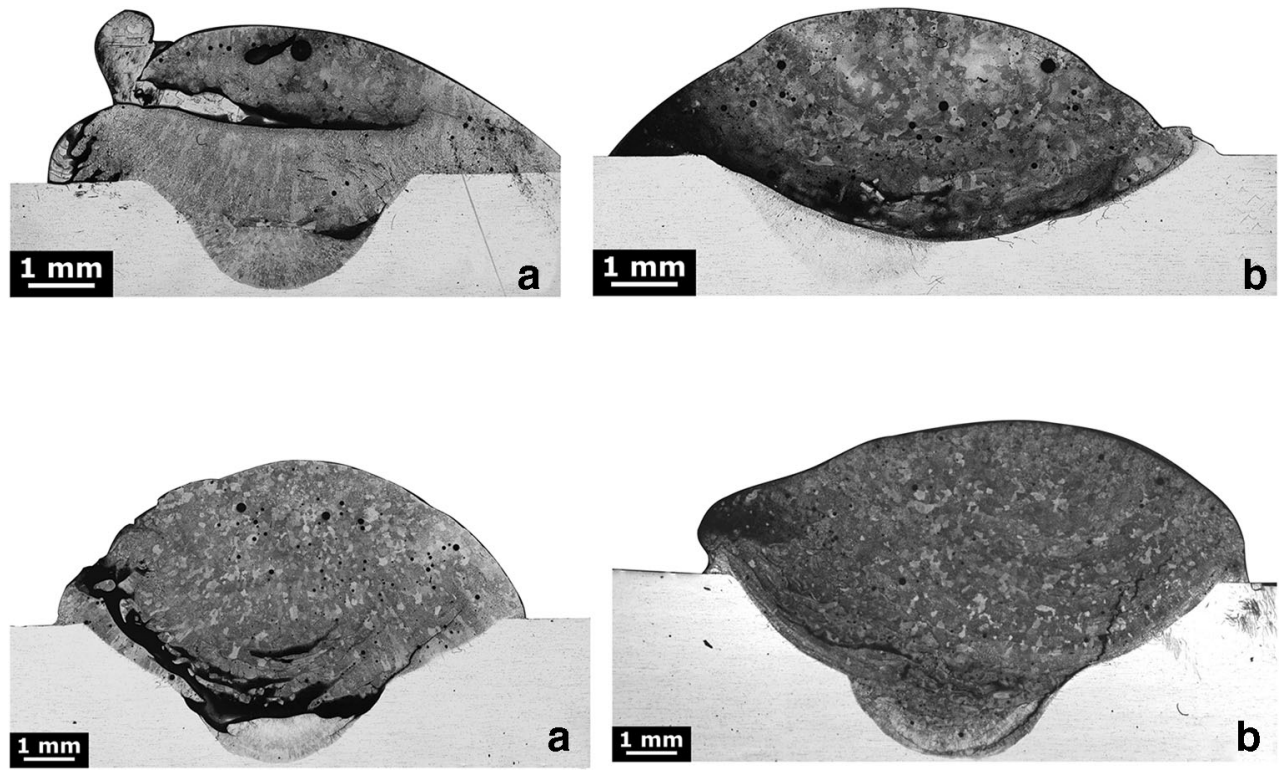
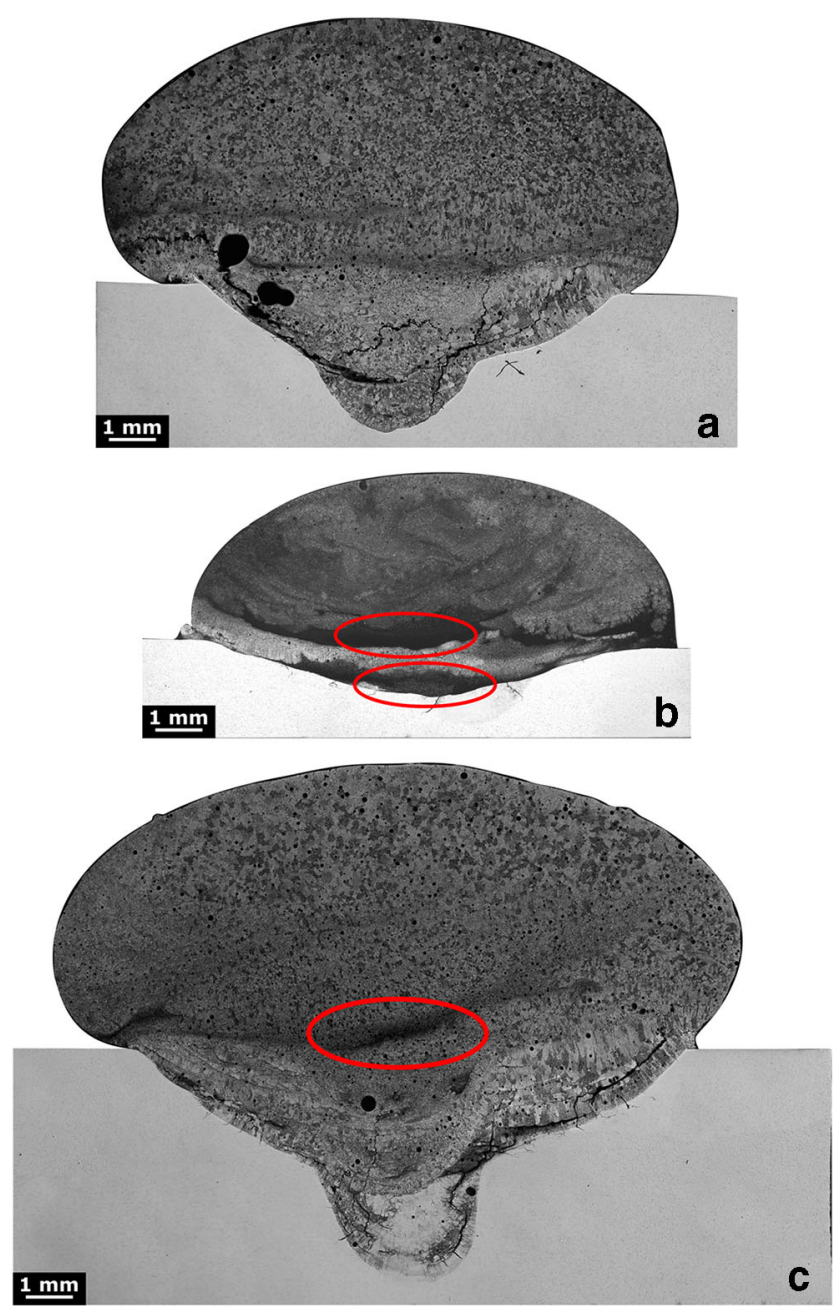

Fig. 8 Cross section of three layer high walls B (a), F (b), and G (c) (see Table 2 for deposition parameters) could be solved by increasing the laser power, as shown in Fig. 6b. As zinc is heavier than aluminium, some process parameters lead to zinc accumulation at the bottom of the beads, as shown in Fig. 7a. Figure $7 \mathrm{~b}$ shows that it was possible to drastically reduce this issue by increasing the WFS of the 2319 wire. This improved mixing capability is coherent with the observations of Kou and Wang [14]. The authors showed that using a higher current slows down the material solidification and increases the electromagnetic forces in the melt pool. Both these phenomena can drastically reduce macro-segregations.

Three sets of parameters were selected for the deposition of three layer high walls: these are shown in Table 2, samples B, $\mathrm{F}$, and $\mathrm{G}$. The cross sections of these 3-dimensional structures are shown in Fig. 8 with sample B, F, and G shown in pictures (a), (b), and (c) respectively. Some issues in the bottom layer with cracks and pores were observed in all three walls. Also, some zinc macro-segregation, highlighted in red, can be seen in pictures (b) and (c). However, in pictures (a) and (c), the top layer microstructure is relatively uniform, with equiaxed grains.

In order to confirm the zinc content of the material, elemental mapping was carried out on the top layer of sample B shown in Fig. 8a: the results are shown in Fig. 9. The SEM image in picture (a) shows some micro-segregation of alloying elements, supported by the aluminium, zinc, and copper maps in pictures (b), (c), and (d). Regardless of micro-segregations issues, which could be due to the very high zinc content, the zinc map shows that zinc was successfully added to the material.

To summarise, the addition of zinc in the melt pool was made possible with Wire Laser Arc deposition. Figures 6 and 7 indicate how process parameters can affect the distribution 
Fig. 9 a SEM image of the deposit and the aluminium (b), zinc (c), and copper map (d)
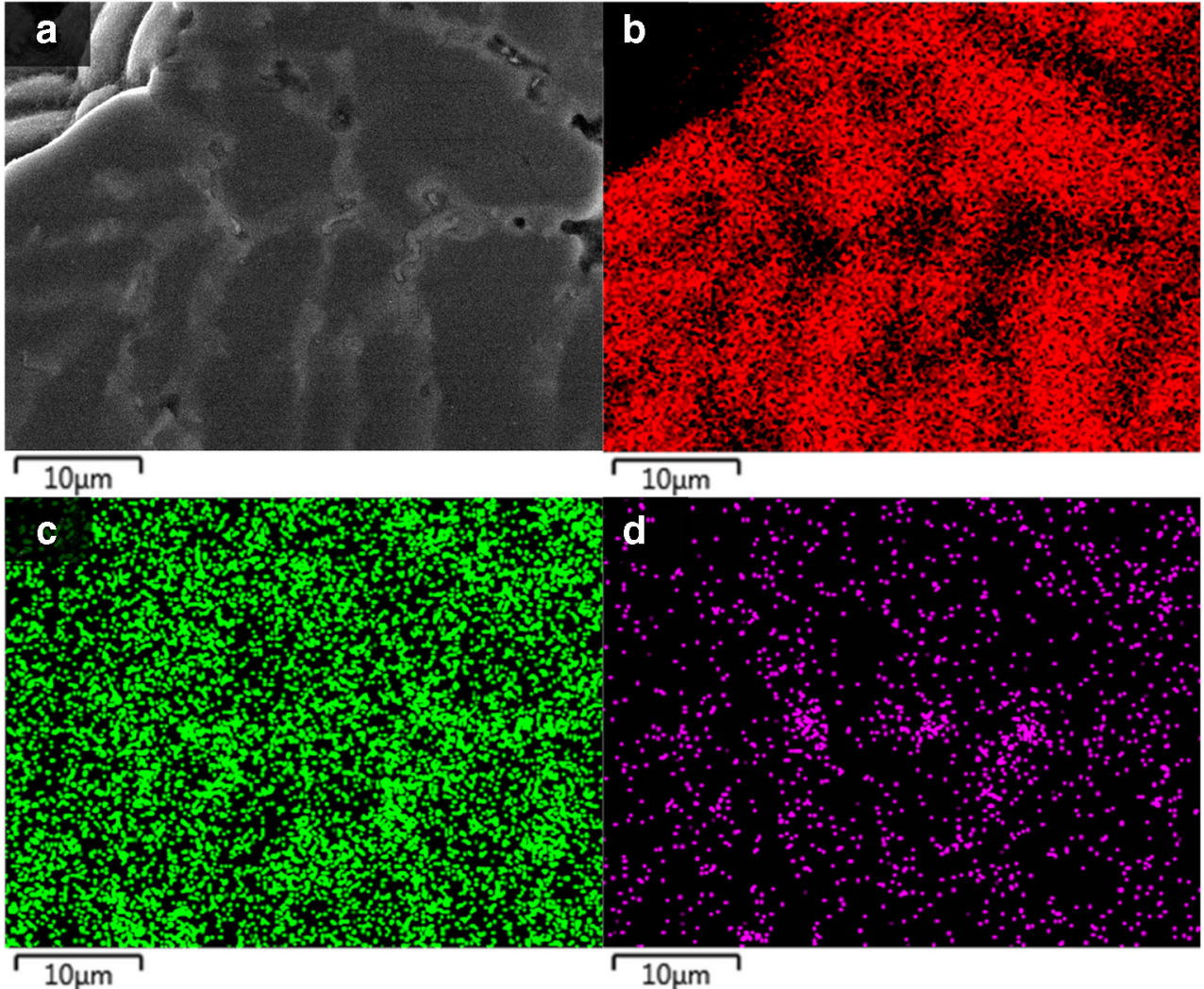

of zinc in the deposited material. The mixing capability of the melt pool depends on the driving forces. Kou detailed these forces [15] and Kou et al. [14] explained how they can promote or be detrimental to melt pool mixing. During GMA welding, the electromagnetic forces tend to promote mixing in the melt pool. The buoyancy force and surface tension gradient together with the electromagnetic forces generate a convection pattern below the melt pool surface. During Wire Laser Arc deposition, the electromagnetic forces depend on the WFS of the main wire, the 2319 wire in the case of this study. The convection pattern is affected by the laser power, laser beam spot size, and the metal transfer of the cold wire. These forces can explain why the different parameters used in this study led to different levels of macro-segregation in the deposited material.

However, the three layer high structures shown in Fig. 8 have a promising micro-structure, with little sign of macrosegregation despite the expected high zinc content, up to $50 \mathrm{wt} \%$ in the wall shown in Fig. 8c.

\section{Conclusion}

Wire Laser Arc Additive Manufacture can be used to deposit aluminium and to produce an elongated melt pool with a stable process. As the laser beam elongated the melt pool behind the electric arc, it was possible to cold feed zinc directly into the melt pool, without impacting on the process stability. For some conditions, the mixing between the two materials was successful, leading to the deposition of an aluminium copper zinc matrix. The possibility of achieving this in situ alloy mixing was shown to be possible for a three-dimensional structure of three-layer height.

In DED, in situ alloying is the only financially applicable solution for composition optimisation. This is because the other path for composition optimisation, the manufacture of customised composition wire, is too expensive, and time consuming to be used during an optimisation by iteration method. This paper shows that WLAAM has great potential in terms of alloy development, even for low boiling point elements such as zinc.

Further work is required to build 3-dimensional high strength aluminium zinc components. The composition of the matrix needs to be optimised to minimise the risk of solidification cracking and increase the material mechanical properties. In order to do so, a mixed aluminium zinc wire should be used as a cold wire, instead of a pure zinc wire. The use of a smaller diameter cold wire would also give a wider working envelope in term of WFS, and therefore composition. The effect of the laser beam diameter and travel speed on the mixing capability of the melt pool and solidification behaviour will also need to be characterised. 
Funding information The authors gratefully acknowledge the funding received from the European Union's Horizon 2020 research and innovation program in the project LASIMM (Large Additive Subtractive Integrated Modular Machine) under the grant agreement No. 723600 as well as the support by Engineering and Physical Sciences Research Council (EPSRC) through the New Wire Additive Manufacturing (grant number EP/R027218/1) research programme.

Open Access This article is licensed under a Creative Commons Attribution 4.0 International License, which permits use, sharing, adaptation, distribution and reproduction in any medium or format, as long as you give appropriate credit to the original author(s) and the source, provide a link to the Creative Commons licence, and indicate if changes were made. The images or other third party material in this article are included in the article's Creative Commons licence, unless indicated otherwise in a credit line to the material. If material is not included in the article's Creative Commons licence and your intended use is not permitted by statutory regulation or exceeds the permitted use, you will need to obtain permission directly from the copyright holder. To view a copy of this licence, visit http://creativecommons.org/licenses/by/4.0/.

\section{References}

1. Williams SW, Martina F, Addison AC, Ding J, Pardal G, Colegrove P (2016) Wire+arc additive manufacturing. Mater Sci Technol 32(7):641-647. https://doi.org/10.1179/1743284715Y.0000000073

2. Starke EA, Staleyt JT (1996) Application of modern aluminum alloys to aircraft. Prog Aerosp Sci 32(95):131-172

3. Gu J, Cong B, Ding J, Williams SW, Zhai Y (2014) Wire+arc additive manufacturing of aluminium. SFF Symp Austin Texas: $451-458$

4. Gu J, Ding J, Williams SW, Gu H, Bai J, Zhai Y et al (2016) The strengthening effect of inter-layer cold working and post-deposition heat treatment on the additively manufactured $\mathrm{Al}-6.3 \mathrm{Cu}$ alloy. $\mathrm{J}$ Mater Process Technol 230:26-34. https://doi.org/10.1016/j. jmatprotec.2015.11.006

5. Ayarkwa KF, Williams S, Ding J (2015) Investigation of pulse advance cold metal transfer on aluminium wire arc additive manufacturing. Int J Rapid Manuf 5(1):44-57
6. Cong B, Ding J, Williams SW (2014) Effect of arc mode in cold metal transfer process on porosity of additively manufactured Al6.3\% Cu alloy. Int J Adv Manuf Technol 76(9-12):1593-1606. https://doi.org/10.1007/s00170-014-6346-x

7. Ryan EM, Sabin TJ, Watts JF, Whiting MJ (2018) The influence of build parameters and wire batch on porosity of wire and arc additive manufactured aluminium alloy 2319. J Mater Process Technol 262(July):577-584. https://doi.org/10.1016/j.jmatprotec.2018.07. 030

8. Bai JY, Yang CL, Lin SB, Dong BL, Fan CL (2015) Mechanical properties of 2219-Al components produced by additive manufacturing with TIG. Int J Adv Manuf Technol 86(1-4):479 485. https://doi.org/10.1007/s00170-015-8168-x

9. Gu J, Bai J, Ding J, Williams S, Wang L, Liu K (2018) Design and cracking susceptibility of additively manufactured $\mathrm{Al}-\mathrm{Cu}-\mathrm{Mg}$ alloys with tandem wires and pulsed arc. J Mater Process Technol 262(May):210-220. https://doi.org/10.1016/j.jmatprotec.2018.06. 030

10. Qi Z, Cong B, Qi B, Sun H, Zhao G, Ding J (2018) Microstructure and mechanical properties of double wire + arc additively manufactured $\mathrm{Al} \mathrm{Cu} \mathrm{Mg}$ alloys. J Mater Process Technol 255(August 2017):347-353. https://doi.org/10.1016/j.jmatprotec. 2017.12.019

11. Woods RA (1979) Metal transfer in aluminum alloys. Weld Res Suppl:59-66

12. Martin JH, Yahata BD, Hundley JM, Mayer JA, Schaedler TA, Pollock TM (2017) 3D printing of high-strength aluminium alloys. Nature 549(7672):365-369. https://doi.org/10.1038/nature23894

13. Aversa A, Marchese G, Manfredi D, Lorusso M, Calignano F, Biamino S, Lombardi M, Fino P, Pavese M (2018) Laser powder bed fusion of a high strength Al-Si-Zn-Mg-Cu alloy. Metals 8(5): 300

14. Kou S, Wang YH (1986) Weld pool convection and its effect. Weld J 65(3):63-70

15. Kou S (2003) Fluid flow and metal evaporation in welding. Welding metallurgy, second edition. Wiley, pp 97-121

Publisher's note Springer Nature remains neutral with regard to jurisdictional claims in published maps and institutional affiliations. 